\title{
Increased count of Bacteroides fragilis in the feces of palmar arsenical keratosis patient
}

\author{
Md. Ashraf Ahmad', Mir Misbahuddin¹ and Sharmeen Ahmed² \\ ${ }^{1}$ Division of Arsenic Research, Department of Pharmacology, Bangabandhu Sheikh Mujib Medical University, \\ Shahbag, Dhaka, Bangladesh; ${ }^{2}$ Department of Microbiology and Immunology, Bangabandhu Sheikh Mujib Medical \\ University, Shahbag, Dhaka, Bangladesh.
}

\begin{tabular}{|c|c|}
\hline \multicolumn{2}{|l|}{ Article Info } \\
\hline Received: & 2 March 2016 \\
\hline Accepted: & 10 August 2016 \\
\hline Available Online: & 21 August 2016 \\
\hline \multicolumn{2}{|c|}{ DOI: 10.3329/bjp.v11i3.29255 } \\
\hline \multicolumn{2}{|c|}{$\begin{array}{l}\text { Cite this article: } \\
\text { Ahmad MA. Misbahuddin M, Ahmed } \\
\text { S. Increased count of Bacteroides fra- } \\
\text { gilis in the feces of palmar arsenical } \\
\text { keratosis patient. Bangladesh J } \\
\text { Pharmacol. 2016; 11: 734-740. }\end{array}$} \\
\hline
\end{tabular}

\begin{abstract}
Chronic exposure to high concentration of arsenic caused an increase in the colony count of Bacteroides fragilis in the feces in comparison to healthy volunteer $\left(3.6 \times 10^{11} \pm 1.9\right.$ vs $1.5 \times 10^{11} \pm 1.7 \mathrm{CFU} / \mathrm{g}$ of feces $)$ which was not statistically significant. But significant increase in the colony count of $B$. fragilis was seen in the feces of palmar arsenical keratosis patient $\left(4.2 \times 10^{11} \pm\right.$ $1.9 \mathrm{CFU} / \mathrm{g}$ of feces; $\mathrm{p}=0.0390$ ). Supplementation with probiotic for 12 weeks decreased the colony counts in all three groups which were not statistically significant among the groups. Probiotics decreased the amount of arsenic in the nail of all the three groups significantly.
\end{abstract}

\section{Introduction}

Chronic ingestion of high concentration of arsenic through drinking water may lead to arsenicosis. Initial symptoms may appear in the skin as melanosis, leucomelanosis and keratosis. Subsequently, the patient may suffer from hypertension, diabetes or cancer. All the members of a family are drinking high concentration of arsenic without having the symptoms of arsenicosis. The reason of this discrepancy is not clear. Therefore, it is necessary to understand its pathogenesis.

The total number of bacteria in the gut is about 10-times the number of human cells. At least 500 different microbial species exist in the intestine, although on a quantitative basis 10-20 genera are predominate (Saarela et al., 2002). About $50 \%$ of the bacteria available in feces belong to Bacteroides, Clostridium coccoides and Eubacterium rectale group (Franks et al., 1998).

When someone drinks arsenic contaminated water, gut bacteria are also exposed to arsenic. It is not clear whether chronic exposure to arsenic changes the number of pattern of gut bacteria. It cannot be exclude the role of gut bacteria in the pathogenesis of arsenicosis. Gut bacteria have been shown to reduce a wide range of toxic metals viz., chromium, mercury, cobalt, lead and arsenic through detoxification and elimination (Upreti et al., 2004). Metabolism of inorganic arsenic by the gastro-intestinal flora may have considerable significance in humans and animals. There was reduction in the number of E. coli in the feces of patients with arsenical keratosis (Rashid et al., 2014). Though, E. coli contributes only about $0.1 \%$ of the total gut bacteria. In the normal adult colon, $96-99 \%$ of the resident bacterial flora consists of anaerobes (Cebra, 1999; Davis, 1996). Some diseases are claimed to be influenced by gut bacteria. It is not known whether anaerobic bacteria play an important role in the pathogenesis of arsenical keratosis.

Supplementation of probiotic and prebiotic can alter the pattern of gut bacteria. These are recommended to use in some diseases. Supplementation for 12 weeks reverses the number of E. coli in the feces of arsenical keratosis (Rashid et al., 2014). 
So, the purpose of this study is tried to identify and count the number of colony of Bacteroides fragilis (anaerobic bacteria) in the feces and also to detect arsenic load in nail of arsenicosis patient. Arsenic exposed controls and healthy volunteer were also taken in this study for comparison.

\section{Materials and Methods}

This study was conducted from April to December 2013 at the Kachua Upazilla of Chandpur District, $100 \mathrm{~km}$ away from Dhaka. A total 17,787 shallow tube wells are present within this Upazilla of which $97.9 \%$ are contaminated with arsenic (>50 $\mu \mathrm{g} / \mathrm{L})$. There were 202 registered patients of arsenicosis at the Upazilla Health Complex.

\section{Participants}

Thirty patients moderate degree arsenical palmer keratosis were recruited randomly. Drinking water was collected once (before starting the study) in order to confirm the diagnosis. Finally 24 cases of arsenicosis were confirmed. As arsenic exposed control, 20 participants were selected from the family members of arsenicosis sufferers. The people $(n=10)$, using green marked tube well water having $<50 \mu \mathrm{g} / \mathrm{L}$ of arsenic, were agreed to participate as healthy volunteer.

\section{Method of collecting the samples}

Drinking water: Drinking water $(50 \mathrm{~mL})$ was collected in the supplied properly labeled containers (containing one/two drops of nitric acid) from all participants and then transported to the Department of Pharmacology on the same day.

Nails: The participants were advised to wash their hands and legs and then dried. Finger and toe nail samples (200-500 mg) were collected and were stored in a dry container.

Feces: Each patient collected his/her feces sample (about $5 \mathrm{~g}$ ) in the previously supplied plastic container with stick immediately after defecation on the day of visit. Then each container was labeled and kept in a gas jar (3.5 L) with gas pack (AnaeroGen-AN0035A, England) for transportation to the laboratory on the same day. On the next day, the anaerobic as well as aerobic cultures of feces were done on the selective $B$. fragilis agar media at the Department of Microbiology. $B$. fragilis were finally identified by aerotolerance test and standard biochemical tests.

\section{Selection of probiotic and prebiotic with maximum efficacy}

Capsules of probiotic and prebiotic combination (same composition and amount from) were collected from the local drug store. There were only three different
Pharmaceutical companies that marketed their products. Colonies of bacteria of these pharmaceutical products were done by CDC anaerobic blood agar media and the gas jar with gas pack. The supplement which showed maximum colonies count was selected for use in this study.

\section{Composition of probiotic-prebiotic capsule}

Each capsule contains Lactobacillus acidophilus (2 billion), Lactobacillus bulgaricus (1 billion), B. bifidum (1 billion) and fructo-oligosaccharides (100 mg). The last one is the prebiotic and others are prebiotic (living non-pathogennic bacteria).

\section{Distribution of drugs}

Each patient received a plastic zipper bag containing 28 capsules (drugs for 2 weeks). They were advised to swallow two capsules daily (at morning and night) after meal, with sufficient amount of drinking water (about $150 \mathrm{~mL}$ ). Immediately after taking the drug, putting a tick mark in the appropriate space printed on a separate compliance sheet.

\section{Selection criteria}

Inclusion criteria include a) gender (both male and female) and b) age (20-60 years). The arsenic exposure was based on the duration of intake of drinking water.

Arsenical palmer keratosis: The subjects who fulfilled the following criteria were recruited as arsenicosis patients: a) who drank arsenic contaminated water $(>50 \mu \mathrm{g} / \mathrm{L})$ for more than 6 months and b) showing physical signs of moderate palmer keratosis.

Arsenic exposed controls: The subject who fulfilled the following criteria was recruited as arsenic exposed control: a) who was the family member of the patient, b) showing no skin manifestations of melanosis, leucomelanosis and palmer keratosis, c) shared same tube well water for drinking and cooking purpose with the patient for more than 6 months and d) had same socioeconomic background as patient

Healthy volunteers: The subject who fulfilled the following criteria was recruited as healthy volunteers: a) who drank arsenic safe water $(<50 \mu \mathrm{g} / \mathrm{L}), \mathrm{b})$ lived in the same Upazilla, c) had no skin manifestation of melanosis, leucomelanosis and keratosis and d) subjects who voluntarily agreed to participate.

Exclusion criteria includes a) patients having age $<18$ and $>60$ years, b) acutely ill patients with other major health problems, such as tuberculosis, hypertension, asthma etc, c) patients getting treatment of arsenicosis like anti-oxidant vitamins and minerals, d) patients already enlisted as participants in other ongoing clinical trials, e) patients had other dermatological and infectious conditions of skin, such as eczema, psoriasis, contact dermatitis, etc, and e) those who did not 
voluntarily agreed to participate and fulfill the above mentioned criteria.

\section{Data collection procedures}

After taking the informed written consent, detailed history was taken by interviewing. Clinical examinations were done mainly based on moderate palmer arsenical keratosis of the participants and recorded in data collection sheet. The result of the study was recorded in separate result sheet.

\section{Anaerobic culture of human feces}

Dilution of feces for culture (Choudhury et al., 2009): One gram of feces was weighed in an analytical electronic balance (PA 214, USA) and was taken in sterile labeled test tube containing $1 \mathrm{~mL}$ of normal saline for dilution and culture. The test tube containing feces was thoroughly mixed by vortex for $2 \mathrm{~min}$ and then centrifuged (Labofuge 200, Germany) at $700 \mathrm{x}$ g for $10 \mathrm{~min}$. Then supernatant was decanted into sterile labeled test tube containing $1 \mathrm{~mL}$ of normal saline.

Then one-tenth serial dilution of the sample was done six times. Test procedure for dilution was repeated for several times with different dilutions till it could be established that countable number of colonies obtained on seventh dilution. About $10 \mu \mathrm{L}$ of the most diluted sample was taken by sterile wire and inoculated in CDC (Centers for Disease Control) anaerobic gentamicin-vancomycin blood agar media and incubated at $37^{\circ} \mathrm{C}$ for 48 hours within the gas jar with gas pack and also in MacConkeys agar media at $37^{\circ} \mathrm{C}$ for 24 hours. Colonies of bacteria were counted after 48 hours. Feces culture was performed on day 0 and day 85 after completion of therapy. Primary anaerobic plates were examined with a hand lens.

Calculation of colony count (Buchanan et al., 1986): Then colonies of bacteria were counted in the following way-If, $n=450$ colonies are grown, the colony count was:

$=450 \times 10^{7} \mathrm{CFU} / \mathrm{mL}$

$=450 \times 10^{9} \mathrm{CFU} / 10 \mu \mathrm{L}$ or $4.5 \times 10^{11} \mathrm{CFU} / 10 \mu \mathrm{L}$

Colony morphology: Colonies of $B$. fragilis on CDC anaerobe blood agar were 1 to $4 \mathrm{~mm}$ in diameter, nonhemolytic, gray, entire and semi opaque, with concentric whorls or ring-like structures inside the colonies were found when examined by hand lens.

Gram stain: A single colony was examined microscopically using gram stain. In Gram stained smears $B$. fragilis were Gram negative rods and often pleomorphic, staining irregularly.

Aerotolerance tests: Aerotolerance test was performed on suspected colonies to confirm that they were anaerobes (Winn et al., 2006). Then four to six colonies from the anaerobic isolation plate were sub-cultured onto two anaerobic blood agar plates; one was incubated aerobically and other was anaerobically at $37^{\circ} \mathrm{C}$ for 48 hours to see any growth. B. fragils was grown on the anaerobic blood agar anaerobically, but not grown on anaerobic blood agar aerobically.

Finally the isolated colonies were identified by fluorescence test under UV light, special-potency antimicrobial identification disc test and other biochemical test including catalase, indole, $\mathrm{H}_{2} \mathrm{~S}$ and bile esculin test.

\section{Estimation of total arsenic}

Estimation of total arsenic in water and nail was done using the SDDC (silver diethyldithiocarbamate) method (Bhuiyan et al., 2015). In brief, arsenic reacts with zinc in presence of acid to produce arsine gas which is scrubbed through lead acetate impregnated glass wool and is absorbed in SDDC. There is development of red color which is due to arsine silver diethyldithiocarbamate reaction. Finally the color is measured by spectrophotometer (wavelength: $535 \mathrm{~nm}$ ).

\section{Results \\ Characteristics of the participants}

The mean $( \pm$ SD) age of arsenicosis patients was $42.1 \pm$ 7.9 years, whereas it was $39.6 \pm 11.7$ years in arsenic exposed controls and $40.4 \pm 6.5$ years in healthy volunteers. That is the mean age of three groups is more or less similar (Table I). The mean $( \pm \mathrm{SD}$ ) duration of arsenic exposure of the arsenicosis patients and arsenic exposed control subjects were $(22.9 \pm 7.4$ and $15.7 \pm 8.3$ years). The mean $( \pm \mathrm{SD})$ duration of symptoms (palmer keratosis) in arsenicosis patients was $8.8 \pm 4.9$ years. All arsenicosis patients $(\mathrm{n}=20)$ showed the manifestation of keratosis in both palm of the hands. The mean $( \pm$ SD) amount of arsenic in the tube well water of healthy volunteers, arsenic exposed controls and arsenicosis patients were $7.2 \pm 5.1 ; 102.4 \pm 66.5$ and $108.9 \pm 64.4 \mu \mathrm{g} /$ $\mathrm{L}$ respectively. Patients and arsenic exposed controls shared same water source.

Colony count of B. fragils in feces before and after consumption of probiotic capsules

The colony count of $B$. fragilis in feces of healthy volunteers was $1.5 \times 10^{11} \pm 1.7 \mathrm{CFU} / \mathrm{g}$ of feces (Figure 1). But it was increased in arsenic exposed controls $\left(3.6 \times 10^{11} \pm\right.$ $1.9 \mathrm{CFU} / \mathrm{g}$ of feces) and were not statistically significant $(p=0.1088)$ when compared with healthy volunteers. But in arsenicosis patients it was increased $\left(4.2 \times 10^{11} \pm\right.$ $1.9 \mathrm{CFU} / \mathrm{g}$ of feces) and these changes were statistically significant $(p=0.0390)$ when compared with healthy volunteers. But when we compared the data of arsenic exposed controls and arsenicosis patients $(p=0.4511)$, the differences were not statistically significant. That means arsenicosis patients showed marked increased level of $B$. fragilis count in feces. 
Table I

Selected characteristics of the participants

\begin{tabular}{|l|ccc|}
\hline Characteristics & Healthy volunteers & Arsenic exposed controls & Arsenicosis patients \\
\hline Number $(\mathrm{n})$ & 7 & 14 & 18 \\
Age (years) & $40.4 \pm 6.5$ & $39.6 \pm 11.7$ & $42.1 \pm 7.9$ \\
Gender & & 7 & 6 \\
Male & 1 & 7 & 12 \\
Female & 6 & $15.7 \pm 8.3$ & $22.9 \pm 7.4$ \\
Duration of arsenic exposure (years) & - & - & $8.8 \pm 4.9$ \\
Duration of symptoms (years) & - & $102.4 \pm 66.5 \mathrm{a}$ & $108.9 \pm 64.4 \mathrm{a}$ \\
\hline
\end{tabular}

Data are presented as mean ( \pm SD); apatients and exposed controls had same source of drinking water; Drop out cases were 3 in healthy volunteers, 6 in arsenic exposed controls and 2 in patients

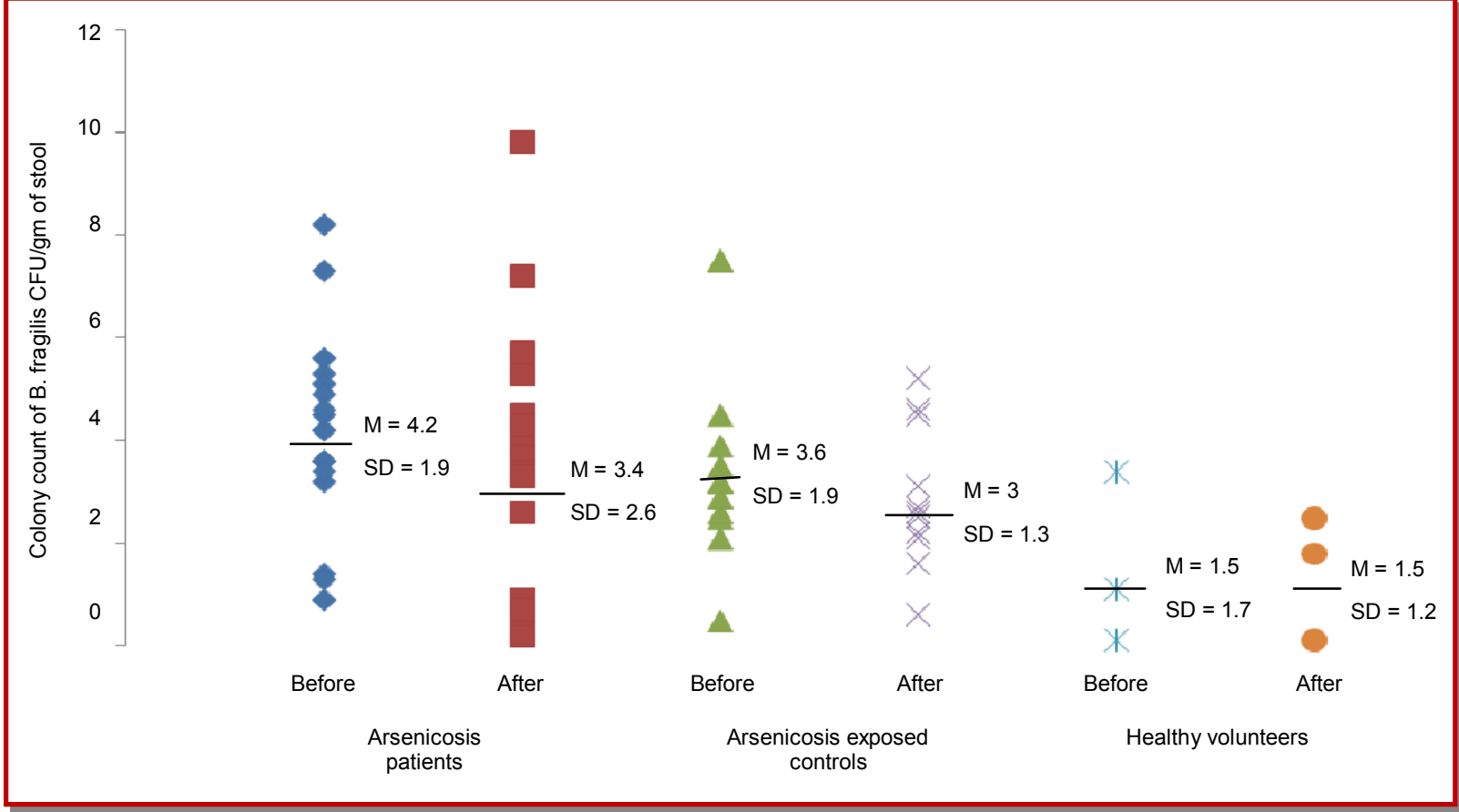

Figure 1: Colony count of B. fragilis in feces in all the three study groups (before and 12 weeks after supplementation of probiotic and prebiotic)

After probiotic supplementation for 12 weeks, colony counts of B. fragilis in feces of all the three groups were decreased. The results were not statistically significant $(p=0.1626)$ in arsenicosis patients, arsenic exposed controls $(p=0.1242)$ and in healthy volunteers $(p=0.9467)$ (Figure 1).

\section{Nail arsenic level before and after consumption of probiotic capsule}

The nail arsenic level of arsenicosis patients was $6.6 \pm$ $1.5 \mu \mathrm{g} / \mathrm{g}$, which is more than the arsenic exposed con- trols $(3.9 \pm 1.1 \mu \mathrm{g} / \mathrm{g})$. The amount is negligible in healthy volunteers $(1.3 \pm 0.6 \mu \mathrm{g} / \mathrm{g})$. When the result were compared with different groups, the comparison between healthy volunteers and arsenicosis patients $(p=0.0001)$, healthy volunteers and arsenic exposed controls $(p=0.0001)$ and, arsenic exposed controls and arsenicosis patients $(p=0.0001)$ were statistically highly significant.

After 12 weeks supplementation of probiotic, the concentrations of arsenic in nail of all the three groups were significantly decreased. The result was statistically 


\begin{tabular}{|c|c|c|c|c|}
\hline \multicolumn{5}{|c|}{ Table II } \\
\hline \multicolumn{5}{|c|}{$\begin{array}{l}\text { Arsenic level in nail of healthy volunteers, arsenic exposed controls and arsenicosis patients both before and } \\
\text { after probiotic supplementation for } 12 \text { weeks }\end{array}$} \\
\hline \multirow[t]{2}{*}{ Group } & \multirow[t]{2}{*}{$\mathrm{n}$} & \multicolumn{2}{|c|}{ Nail arsenic level $(\mu \mathrm{g} / \mathrm{g})$} & \multirow[t]{2}{*}{$P$ value } \\
\hline & & Before & After & \\
\hline Healthy volunteers $(\mathrm{H})$ & 7 & $1.3 \pm 0.6$ & $0.5 \pm 0.2$ & 0.0204 \\
\hline Arsenic exposed controls (A) & 14 & $3.9 \pm 1.1$ & $1.9 \pm 1.2$ & 0.0001 \\
\hline \multirow[t]{4}{*}{ Arsenicosis patients $(\mathrm{P})$} & 15 & $6.6 \pm 1.5$ & $3.8 \pm 1.3$ & 0.0001 \\
\hline & $\mathrm{H}$ vs A & & & 0.0001 \\
\hline & $\mathrm{H}$ vs $\mathrm{P}$ & & & 0.0001 \\
\hline & A vs $P$ & & & 0.0001 \\
\hline
\end{tabular}

Data are presented as mean $( \pm \mathrm{SD})$; Compared the data of before supplementation with 12 weeks after supplementation; Comparison done- $\mathrm{H}$ vs A: Healthy volunteers vs. arsenic exposed controls (before supplementation); H vs P: Healthy volunteers vs. arsenicosis patients (before supplementation); A vs P: Arsenic exposed controls vs arsenicosis patients (before supplementation); Failed to collect nail samples from 3 patients

very significant in arsenicosis patients $(p=0.0001)$ and in arsenic exposed controls $(p=0.0001)$, than in healthy volunteers $(p=0.0204)$, (Table II).

\section{Discussion}

The present study showed that the colony counts of $B$. fragilis were increased in arsenic exposed controls (not statistically significant) and arsenicosis patient (statistically significant) when compared to healthy volunteers. There was significant increase in nail arsenic level of both arsenic exposed controls and arsenicosis patient. After 12 weeks supplementation with probiotic-prebiotic, the colony counts of $B$. fragilis in feces of all the three groups were decreased (statistically not significant). On the other hand, the concentrations of total arsenic in nails of all the three groups were significantly decreased.

This is the first report where we showed that chronic arsenic consumption increased the colony counts of anaerobic bacteria such as $B$. fragilis in human. However, the numbers of other anaerobic bacteria are not known. There are only three reported studies of which two were on rat and one on arsenicosis patient.

Chronic consumption of arsenic through drinking water and foodstuffs increases the concentration of arsenic within the body. We usually estimate the amount of arsenic in hair, nail and urine. Presence of high concentration of total arsenic in hair or nail indicates the longtime exposure whereas its presence in urine indicates recent exposure. The amount of arsenic in nail is higher than hair. It is difficult to collect the hair sample from the root (Samantaa et al., 2004). It is quite natural that, this study shows that nails contain high concentration of arsenic in arsenic exposed and arsenicosis patients.

After 12 weeks supplementation of probiotic-prebiotic, the colony count of $B$. fragilis was decreased in both arsenicosis patients and arsenic exposed controls. Surprisingly, we found that, after probiotics supplementation the colony count of arsenicosis patients were reduced but not significantly as to the level of the healthy volunteers. But in case of arsenic exposed control the number of $B$. fragilis was decreased but not as much as arsenicosis patients.

On the contrary, a significant increased in gut bacterial count (except B. fragilis) may occur after probiotics supplementation that is suggestive of increased intestinal detoxification of arsenic following increased bacterial multiplication. Detoxification of arsenic by gut bacteria is genetically mediated through arsenicinducible operon in the chromosome as confirmed by Dorio et al. (1995) using chromosomal lacZ transcription fusion library.

After 12 weeks supplementation of probiotic-prebiotic, there was significant reduction of nail arsenic level in healthy volunteers but highly significant change occurred in arsenicosis patients and arsenic exposed controls. That means, after probiotic-prebiotic supplementation body arsenic load was diminished.

Accumulation of arsenic was seen in $-\mathrm{SH}$ group rich organs, particularly in hair, skin and nail (Baldwin and Marshall, 1999). There is a positive correlation between the concentration of arsenic in drinking water and the 
level of arsenic in nails (Ali et al., 2010); suggesting that the measurement of arsenic concentration in nails can be one of the important markers of chronic arsenic toxicity (Karagas et al., 1996; Caussy, 2005).

Manipulation of the human intestinal flora offers potentially to improve health issue through a variety of mechanisms (Salminen et al., 1998). Probiotic bacteria are known to be promoters of the host body's defense mechanism by stabilizing the local microflora, triggering a humoral immune response and constructing a barrier against immunological disorder. Researchers consider that probiotic microorganisms can shape the immune system both local and at systemic level which will allow the future probiotics as treatment of many diseases in humans and animals (Corcionivoshi et al., 2010). Probiotics are possibly the most natural and safe means of maintaining this balance (Chukeatirote, 2003).

Moreover, the anaerobic gut bacteria play a vital role in regulating the number of aerobic bacteria through a synergistic activity and also regulate gastro intestinal epithelial growth and development of diffuse GALT and thereby play an important role in gastro-intestinal pathophysiology (Salminen et al., 1998).

\section{Conclusion}

Patients of palmar arsenical keratosis showed an increase in the colony count of Bacteroides fragilis in the feces. Supplementation with probiotic for 12 weeks decreased the colony counts in all three groups which were not statistically significant among the groups. Probiotics decreased the amount of arsenic in the nail of all the three groups significantly.

\section{Ethical Issue}

A protocol containing the aims and objectives, research questions and procedure were submitted to the Institutional Review Board of Bangabandhu Sheikh Mujib Medical University for approval (registered in www.clinicaltrials.gov No. NCT01726426). All the participants were informed about the nature and purposes of the study and what outcome they could expect being a participant.

\section{Conflict of Interest}

All authors have completed the ICMJE uniform disclosure form and declare no support from any organization for the submitted work.

\section{References}

Ahmad SA, Faruquee MH, Sayed MHSU, Khan MH, Hadi SA,
Khan AW. Chronic arsenic poisoning: Management by vitamins A, E, C regimen. J Prev Social Med. 1998; 17: 19-26.

Ali N, Haque MA, Haque A, Salam KA, Karim MR, Rahman A, Islam K, Saud ZA, Khalek MA, Akhand AA, Hossain M, Mandal A, Karim MR, Miyataka H, Himeno S, Hossain K. Association between arsenic exposure and plasma cholinesterase activity: A population based study in Bangladesh. Environ Health. 2010; 9: 1-9.

Baldwin DR, Marshall WJ. Heavy metal poisoning and its laboratory investigation. Ann Clin Biochem. 1999; 36: 267300.

Bhuiyan HA, Tshering K, Misbahuddin M. Estimation of arsenic in nail using silver diethyldithiocarbamate method. Bangladesh J Pharmacol. 2015; 10: 513-17.

Caussy D. A field guide for detection, management and surveillance of arsenicosis cases. World Health Organization, Regional Office for South-East Asia, New Delhi, 2005.

Choudhry ZK, Misbahuddin M, Hosain AKMM, Saleh AA. Inhibitory effect of arsenic on aerobic gut flora in rat. Bangladesh Med Res Coun Bull. 2009; 35: 79-83.

Chukeatirote E. Potential use of probiotics. Songklanakarin J Sci Technol. 2003; 25: 275-82.

Corcionivoschi N, Drinceanu D, Stef L, Luca I, Julean C, Mingyart O. Probiotics-identification and ways of action. Innov Rom Food Biotechnol. 2010; 6: 1-11.

Dorio C, Cai J, Marmor J, Shinder R, Dubow MS. An Escherichia coli chromosomal ars operon homolog is functional in arsenic detoxification and is conserved in gram negative bacteria. J Bacteriol. 1995; 177: 2050-56.

Franks AH, Marmsen HJM, Raangs GC, Jansen GJ, Schut F, Welling GW, 1998. Variations of bacterial populations in human feces measured by fluorescent in situ hybridization with group-specific $16 \mathrm{~S}$ rRNA-targeted oligonucleotide probes. Appl Environ Microbiol. 1998; 64: 3336-45.

Islam AZMM, Sikder S, Biswas AK, Islam Z, Hadiuzzaman, Misbahuddin $M$, et al. Randomized controlled trial to evaluate the effectiveness of topical use of salicylic acid for treatment of keratosis in arsenicosis patient. In: Applied research on arsenic in Bangladesh. Misbahuddin (ed). Dhaka, Directorate General of Health Services and World Health Organization, 2007, pp 93-102.

Jorge Y, Fierro V, Mansilla H, Figueroa L, Cornejo L, Barnes RM. Arsenic speciation in human hair: A new perspective for epidemiological assessment in chronic arsenicism. J Environ Monitor. 2005; 7: 1335-41.

Kaila M, Isolauri E, Saxelin M, Arvilommi H, Vesikari T. Viable versus inactivated lactobacillus strain GG in acute rotavirus diarrhoea. Arch Dis Child. 1995; 72: 51-53.

Karagas MR, Morris JS, Weiss JE, Spate V, Baskett C, Greenberg ER. Toenail samples as an indicator of drinking water arsenic exposure. Cancer Epidemiol Biomarkers Prev. 1996; 5: 849-52.

Misbahuddin M, Islam AZMM, Khandker S, Mahmud IA, Islam N, Anjumanara. Efficacy of spirulina extract plus zinc in patients of chronic arsenic poisoning: A randomized placebo-controlled study. Clin Toxicol. 2006; 44: 1-7. 
Qin J, Rosen BP, Zhang Y, Wang G, Franke S, Rensing C. Arsenic detoxification and evolution of trimethylarsine gas by a microbial arsenite S-adenosylmethionine methyltransferase. PNAS. 2006; 103: 2075-80.

Rashid N, Misbahuddin M, Choudhry Z, Saleh A, Sattar ANI. The colony count of Escherichia coli in the stool of palmar arsenical keratosis following probiotics supplementation. Bangladesh J Pharmacol. 2014; 9: 176-81.

Ratnaike RN. Acute and chronic arsenic toxicity. Postgrad Med J. 2003; 79: 391-96.

Saarela M, Lahteenmaki L, Crittenden R, Salminen S, MattilaSandholm T. Gut bacteria and health foods: The European perspective. Int J Food Microbiol. 2002; 78: 99-117.

Salminen S, Bouley C, Ruault MCB, Cummings JH, Franck A, Gibson GR, et al. Functional food science and gastrointestinal physiology and function. Brit J Nutr. 1998; 80: 147-
71.

Samantaa G, Sharmaa R, Roychowdhury T, Chakraborti D. Arsenic and other elements in hair, nails, and skin-scales of arsenic victims in West Bengal, India. Sci Total Environ. 2004; 326: 33-47.

Stylbo M, Drobna Z, Jasper I, Lin S, Thomas DJ. The role of biomethylation in toxicity and carcinogenicity of arsenic: A Research update. Environ Health Perspect. 2002; 110: 767-71.

Upreti RK, Shrivastava R, Chaturvedi UC. Gut microflora and toxic metals: Chromium as a model. Indian J Med Res. 2004; 119: 49-59.

Winn WJ, Allen S, Janda W, Koneman E, Procop G, Schreckenberger $\mathrm{P}$. The anaerobic bacteria. In: Koneman's color atlas and textbook of diagnostic microbiology. Koneman EW (ed). $6^{\text {th }}$ edi. 2006, pp 709-77. 


\section{Your feedback about this paper}

1. Number of times you have read this paper

2. Number of times you have seen the video clip

3. Quality of paper

4. Your comments 